\title{
Fluorescence microscopy in colonic exfoliative cytology
}

\author{
D. J. OAKLAND
}

From Queen Elizabeth Hospital, Birmingham

Since the introduction of the exfoliative cytological technique in clinical practice, particularly in the diagnosis of malignant disease of the female genital tract, many authors (Friedman, 1950; Mellors and Silver, 1951; von Bertalanffy, Masin, and Masin, 1956; Liu, 1961) have endeavoured to reduce the time required for scanning the smears by the use of fluorescent microscopy. In this new technique, they have employed fluochromes to stain the smears, and then scanned them, using an ultra-violet microscope unit. Although this technique reduces the scanning time, since the microscopist need only inspect areas on the slide which are fluorescing, recent work (Caspersson, and Santesson 1942; Bertalanffy, 1960) appears to suggest that the technique of recognizing malignant cells by demonstrating their cytochemical composition may be as reliable as the morphological criteria used by Papanicolau and Traut (1941).

A series of smears has been examined using a fluorescent microscopy technique, and acridine orange, as the fluochrome with a view to reducing the time required to scan the material collected from the colon. The findings are briefly reported.

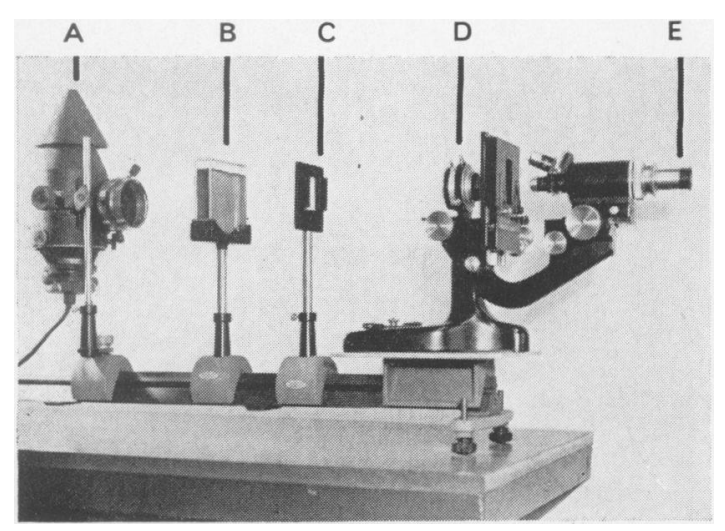

FIG. 1. Fluorescent microscope unit. A high pressure mercury vapour bulb in lamp house with built-in collecting lens. B Five percent ammonical copper sulphate solution in optical glass chamber, C Square (2 in.) glass filter holder for alternative transmission filters. D Dark ground condenser. E Eye-piece with pale yellow suppression filter.
APPARATUS

The fluorescent microscope unit (Fig. 1) used was similar to that described by Armstrong (1957) and the smears were stained with acridine orange using the technique of von Bertalanffy et al. (1956). Some difficulty was experienced in providing adequate illumination of the smear for use with both low-power and high-power objectives, and Smiles (1958) recommended that ideally a special dark-ground condenser should be computed for this work.

\section{FLUORESCENT MICROSCOPIC APPEARANCE OF NORMAL AND ABNORMAL EXFOLIATED COLONIC CELLS}

Under the low-power objective, the cellular content of the smears appeared as numerous points of light on a dark background. Closer inspection under the low-power objective revealed that some of the fluorescing objects were cells and others were inert debris, chiefly strands of mucus (Fig. 2). With acridine orange as the fluochrome, the ribonucleic acid (R.N.A.) in the cytoplasm and in the nucleolus fluoresced bright red, and the desoxyribonucleic

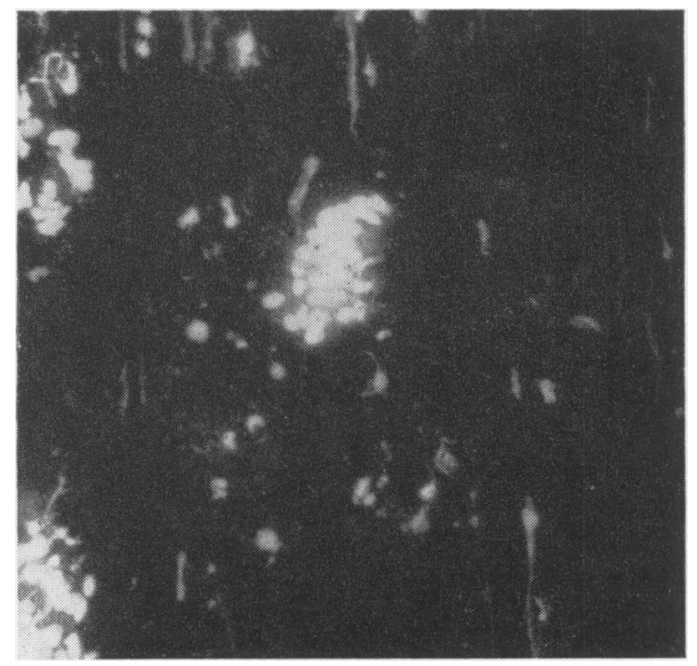

FIG. 2. A typical low-power field of fluorescing cells and mucus in a smear of material from the colon $\times 120$. 


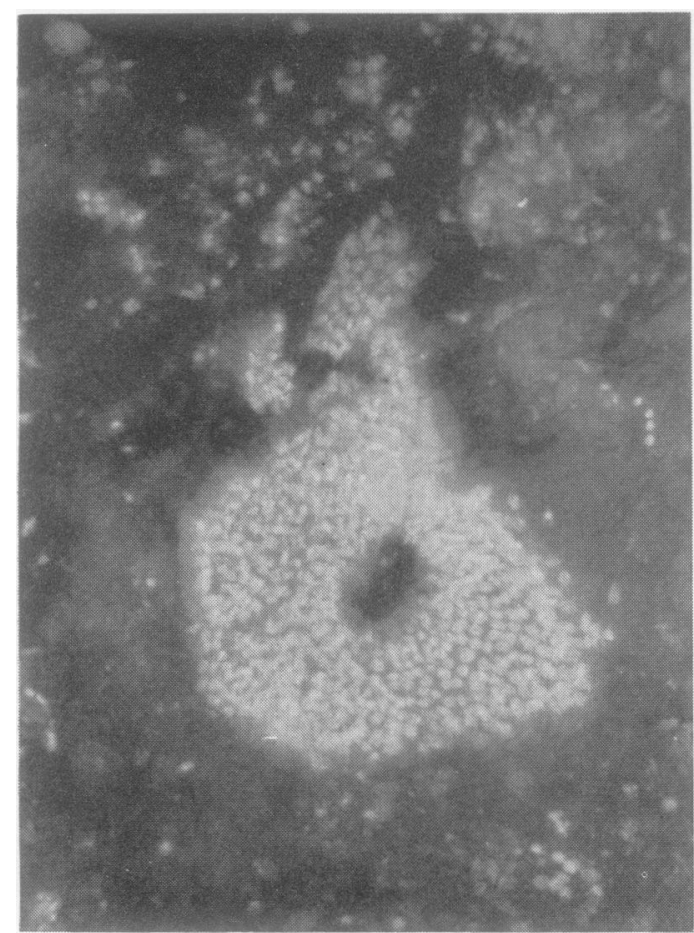

FIG. 3a

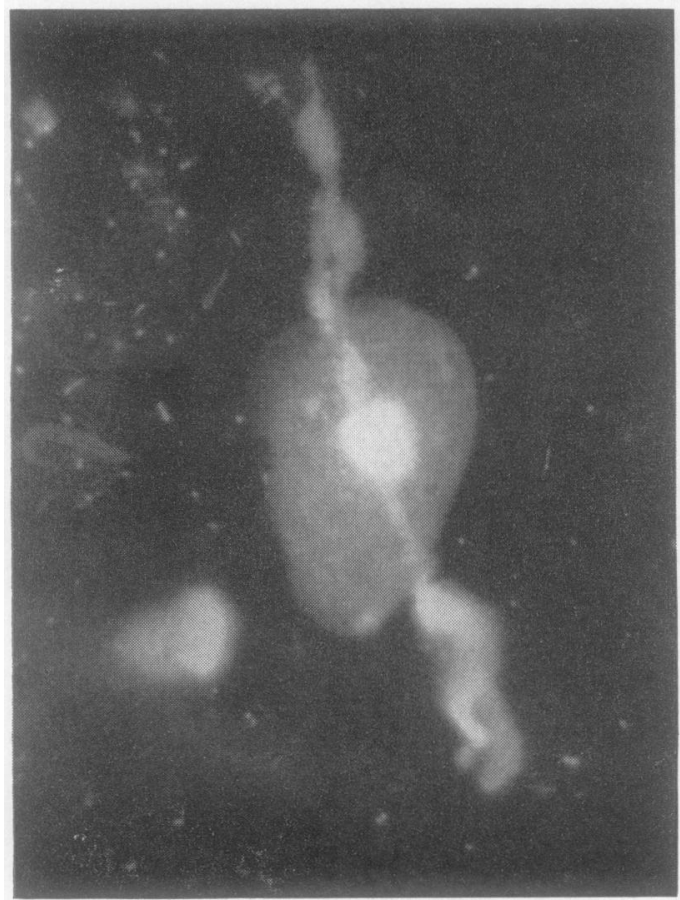

FIG. 3c

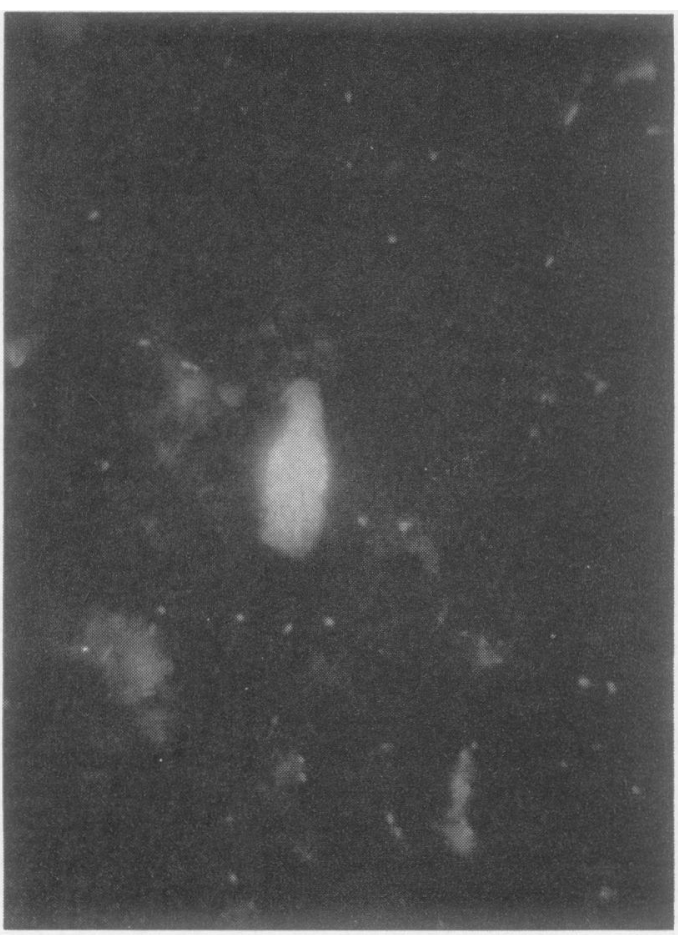

FIG. 3b

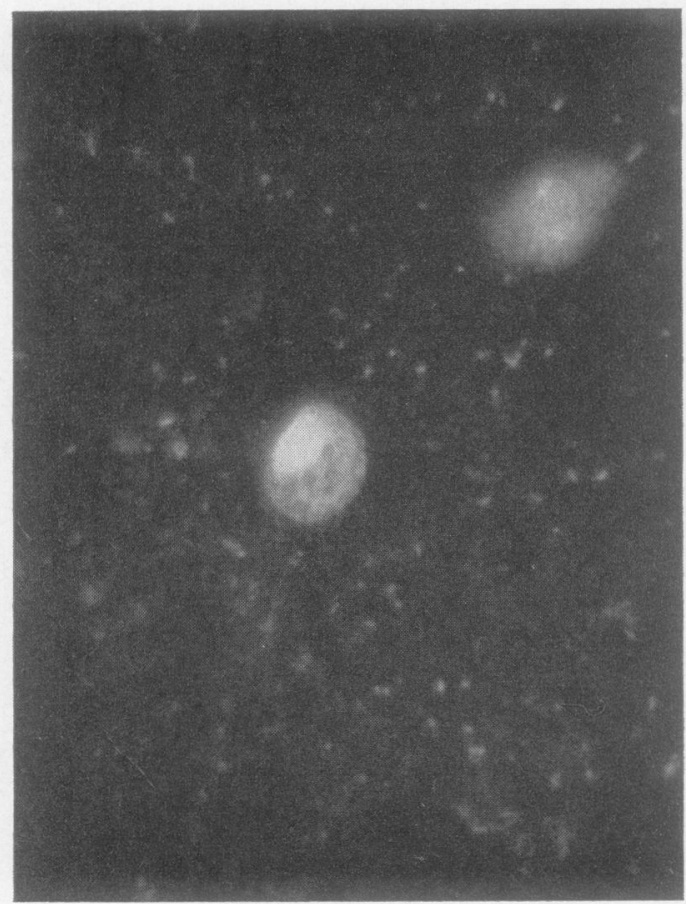

FIG. 3d

FIG. 3. High-power photomicrograph of fluorescing normal cells. (a) A sheet of normal columnar epithelial cells $\times 120 ;($ b) a single columnar epithelial cell $\times 480$; (c) squamous cell with overlying strand of mucus $\times 480 ;(d)$ histiocyte with background of fluorescing bacteria $\times 480$. 
acid (D.N.A.) in the nuclear chromatin fluoresced green or greenish-yellow. The varying content of these two substances in the cells determined the degree of fluorescence and their appearance.

SQUAMOUS EPITHELIAL CELLS The cytoplasm of these cells (Fig. 3c) is grey with a faint greenish tinge, whereas the nucleus fluoresces green. In Fig. $3 c$ the strand of fluorescing material running across the squame is mucin which fluoresces yellow-green.

COlumNar EPITHELIAL Cells The feature of these cells (Figs. 3a and 3b) was the orange fluorescence of the cytoplasm. The nucleus fluoresced green and no orange fluorescence was seen within the nuclear membrane of the normal columnar epithelial cells.

POLYMORPHONUCLEAR LEUCOCYTES The nucleus of the cells fluoresced a bright green-white and when aggregated in groups they produced intense areas of fluorescence on a smear. The cytoplasm was grey and often difficult to distinguish.

HISTIOCYTES These cells were easily recognized with acridine orange staining, the foamy cytoplasm with a roughened edge fluorescing a grey-green colour

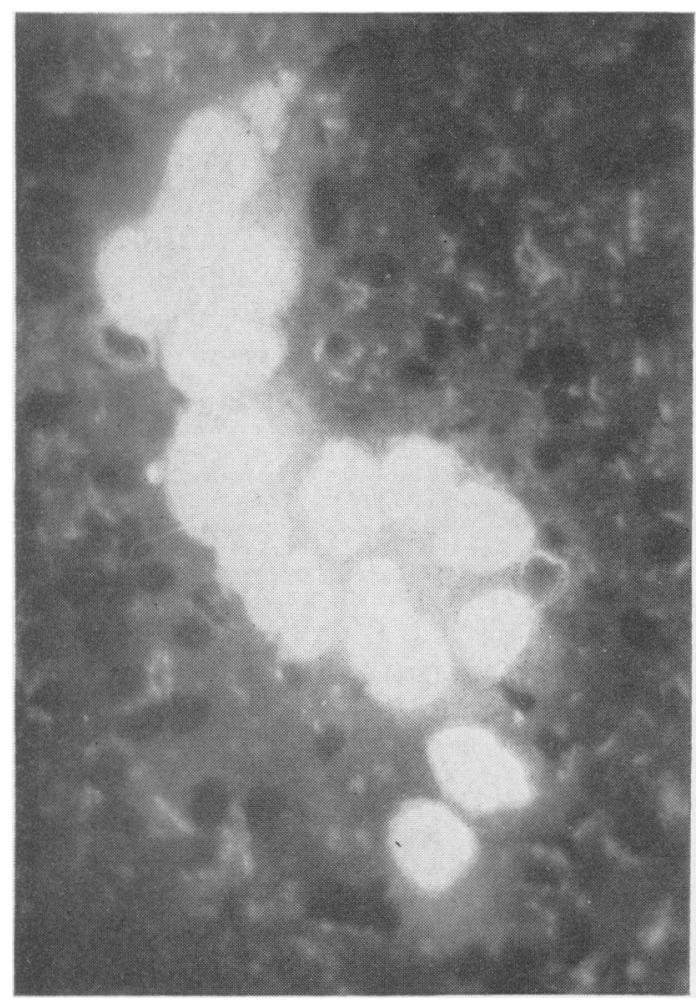

FIG. 4. High-power photomicrograph of a group of exfoliated malignant cells from the large bowel $\times 480$.
(Fig. 3d). The eccentrically placed nucleus fluoresced green.

BACTERIA AND SPORES Bacteria fluoresce orange-red and were visible as small points of light on all the smears, as, for example, in Figure 3d. Spores fluoresced in a similar bright orange.

FAECAL DEBRIS Faecal material in the smears, as stained to a varying degree by the acridine orange and if present in any quantity, fluoresced a dull orange colour, presumably due to the large bacterial content.

MALIGNANT CELLS FROM ADENOCARCINOMA OF THE LARGE BOWEL The nuclei of the malignant cells fluoresced a very bright yellow-green, the yellow content of the nucleus being in contrast with the nuclei of normal columnar cells. Some of the malignant nuclei in freshly stained specimens contained small areas of orange-red fluorescence. These red areas became less obvious if the specimens had been exposed to the ultra-violet light for any length of time. The cytoplasm of the malignant cells fluoresced bright orange-red, and in some cases the fluorescence had a yellowish quality which differed from the fluorescence of the cytoplasm of the

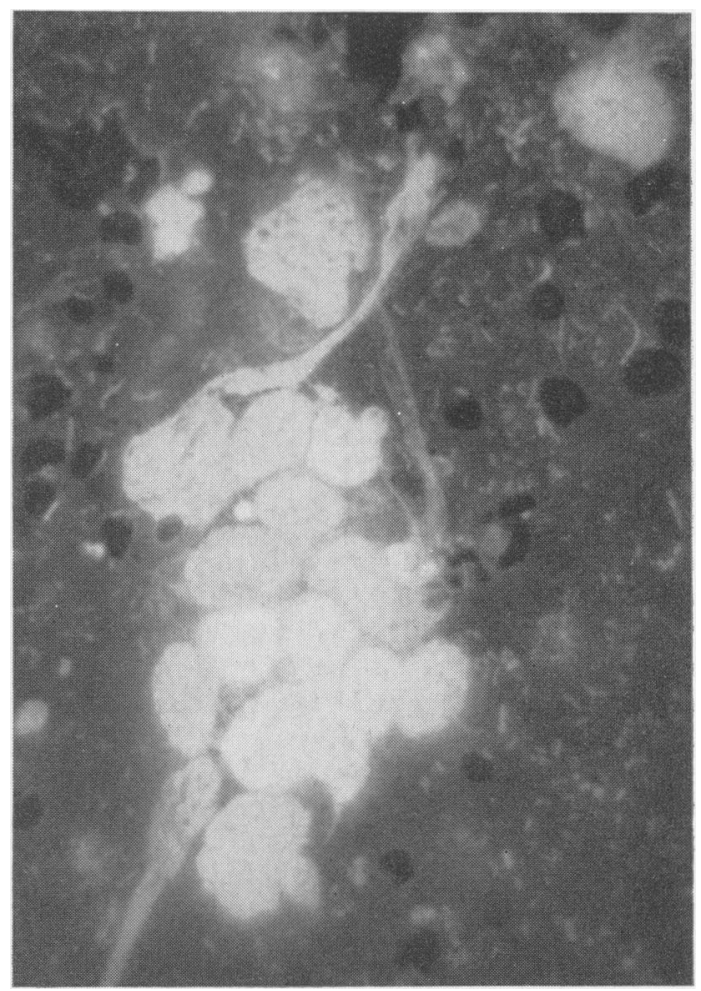

FIG. 5. High-power photomicrograph of a group of exfoliated malignant cells, showing nucleur budding $\times 480$. 
normal columnar epithelial cells. Apart from the bright fluorescence of the malignant nuclei, which together with their increased size caused them to stand out on the black background of the smear, the typical morphology of the malignant nuclei stood out well. Figures 4 and 5 show groups of fluorescing malignant cells with bright yellow-green nuclei. The variation in shape and size of the nuclei is very obvious, and also budding, a less common feature of malignant nuclei, is seen in two of the nuclei. Red blood cells were only seen if the material had been fixed in formalin and they then showed a faint greyish fluorescence.

\section{CONCLUSIONS}

Exfoliative cytology has proved its worth as a method of detecting cancer of the gastro-intestinal tract (Raskin, Kirsner, and Palmer, 1958; Oakland, 1961; Schade, 1960; Burn and Sellwood, 1962), and it now remains to explore any method which reduces the time required to examine the material, so that the technique can be used to screen patients who are suspect or at risk (Day, 1961), for example those suffering from ulcerative colitis.

The method of collecting specimens from the colon by saline lavage results in larger quantities of material to process and examine than in the now well-established gynaecological technique. Six to 10 slides are required for the material collected from a well-prepared colon compared with the one or two slides for gynaecological material. In this respect there is no doubt that the staining technique using acridine orange is quicker than the more complex Papanicolau technique.

There is no difficulty is setting up an adequate ultra-violet microscope unit using a dark ground condenser. Theoretically, acridine orange fluoresces most brightly when excited by light energy of a wavelength of $365 \mathrm{~m} \mu$ (Porro, Dadik, Green, and Morse, 1963). For practical purposes excellent fluorescence is obtained using a Mazda mercury vapour lamp as a light source and a single ammoniacal copper sulphate filter to absorb the red end of the visible spectrum. For routine scanning no advantage has been gained by the use of transmission filters limiting the wavelength of the light energy to the region of $365 \mathrm{~m} \mu$.

The use of a microscope mounted in the horizontal position on an optical bench is convenient for initial work and photography, but for scanning it is more comfortable to have the microscope in the usual inclined vertical position and a polished aluminium mirror to reflect the light.

Smears stained by this technique can be scanned more quickly than by the conventional method using the Papanicolaou stain and white light microscopy. Most smears $(5 \times 2 \mathrm{~cm}$. $)$ can be scanned in three minutes which means that all the material from a colonic washing can be examined in under 30 minutes.

The early hope that malignant cells would stand out brilliantly on a dark background was not entirely realized because of the fluorescence from strands of mucus, bacteria, and groups of polymorphonuclear leucocytes. However, the exfoliated malignant cells can be easily recognized by their bright fluorescence and, when present, by the particular flame-red fluorescence of the cytoplasm. In freshly stained cells the red spots of ribonucleic acid in the nucleoli are a particular feature of malignant cells but these tend to fade fairly quickly. Despite the brighter fluorescence of malignant cells, the final classification may still depend on morphological features. These are usually easily seen, but in case of doubt the smear can be rapidly de-stained in alcohol and re-stained by the Papanicolau (1942) method for final evaluation.

I would like to acknowledge the help of Dr. J. A. Armstrong and M. J. Smiles in setting up a fluorescent microscope unit, and to thank Mr. H. Sharpe for technical assistance. The work was undertaken with the aid of grants from the United Birmingham Hospitals Endowment Fund and the British Empire Cancer Campaign.

\section{REFERENCES}

Armstrong, J. A. (1957). Fluorescence Microscopy in Biology. The Times Science Review. Techniques of Research. 18, 6-9.

Bertalanffy, L. von., Masin, F., and Masin, M. (1956). Use of acridineorange fluorescence technique in exfoliative cytology. Science, 124, 1024-1025.

Bertalanffy, F. D. (1960). Fluorescence microscopy for cytodiagnosis of cancer. Postgrad. Med., 28, 627-633.

Burn, J. I., and Sellwood, R. A. (1962). The results of exfoliative cytology studies in $\mathbf{5 0}$ patients with symptoms of large bowel disorder. Gut, 3, 32-37.

Caspersson, T., and Santesson, L. (1942). Studies on protein metabolism in the cells of epithelial tumours. Acta. Radiol. (Stockh.), Suppl., 46, 1-105.

Day, E. (1961). Practical aspects of cancer detection: selection of patients. Med. Clin. N. Amer., 45, 503-511.

Friedman, H. P., Jr. (1950). The use of ultraviolet light and fluorescent dyes in the detection of uterine cancer by vaginal smear. Amer. J. Obstet. Gynec., 59, 852-859.

Liu, W. (1961). Fluorescence microscopy in exfoliative cytology. Arch. Path., 71, 282-285.

Mellors, R. C., and Silver, R. (1951). A microfluorometric scanner for the differential detection of cells: application to exfoliative cytology. Science, 114, 356-360.

Oakland, D. J. (1961). The diagnosis of carcinoma of the large bowel by exfoliative cytology. Brit. J. Surg., 48, 353-362.

Papanicolau, G. N., and Traut, H. F. (1941). The diagnostic value of vaginal smears in carcinoma of the uterus. Amer. J. Obstet. Gynec., 42, 193-206.

- (1942). A new procedure for staining vaginal smears. Science, 95, 438-439.

Porro, T. J., Dadik, S. P., Green, M., and Morse, H. T. (1963). Fluorescence and absorption spectra of biological dyes. Stain Technol., 38, 37-48.

Raskin, H. F., Kirsner, J. B., and Palmer, W. L. (1958). In Modern Trends in Gastro-enterology, 2nd series, edited by F. Avery Jones, pp. 76-79. Butterworths, London.

Schade, R. O. K. (1960). Gastric Cytology, pp. 38-40. Arnold, London. Smiles, J. (1958). Personal communication. 